\title{
Robust autophagy in optic nerves of experimental Creutzfeldt- Jakob disease and Gerstmann-Sträussler-Scheinker disease
}

\author{
Pawel P. Liberski ${ }^{1}$, Agata Gajos ${ }^{2}$, Andrzej Bogucki² \\ ${ }^{1}$ Department of Molecular Pathology and Neuropathology, Chair of Oncology, Medical University of Lodz, ${ }^{2}$ Department of Extrapyramidal \\ Diseases, Chair of Rehabilitation, Medical University of Lodz, Poland
}

\begin{abstract}
We report here autophagy in the optic nerve in experimental Gerstmann-Sträussler-Scheinker disease (GSS) (Fujisaki-1) in mice and experimental Creutzfeldt-Jakob disease (CJD) (Echigo-1) in hamsters. Lesions of both experimental GSS in mice and experimental CID in hamsters were practically indistinguishable. Briefly, they consisted of widespread Wallerian degeneration, spongiform change and a glial reaction. Numerous axonal swellings were seen. The latter were filled with numerous mitochondria and lysosomal electron-dense bodies. Autophagic vacuoles defined as structures bound in double membranes were readily found in many neuronal processes. The following description is organized as a sequence; however, the changes were all observed in the same specimens. First several empty double membrane-bound autophagic vacuoles were seen. In several of those vacuoles, the inner membrane was separated from the outer membrane and enclosed cargo. At the final stage, a mixture of empty autophagic vacuoles and electron-dense lysosomal vesicles was seen. Dystrophic neurites filled with a mixture of mitochondria, empty autophagic vacuoles and electron-dense lysosomal vesicles were interpreted as the final stage of autophagy. Of note, several areas were replaced with dense astrocytic gliosis.
\end{abstract}

Key words: autophagy, prion diseases, optic nerve.

\section{Introduction}

Prion diseases include kuru, Creutzfeldt-Jakob disease (CJD), Gerstmann-Sträussler-Scheinker disease (GSS) and fatal familial insomnia (FFI) in humans; scrapie in sheep, goats and mouflons; transmissible mink encephalopathy in ranch-reared mink; bovine spongiform encephalopathy in cattle and antelopes or domestic cats, cheetah and tigers in zoological gardens; and chronic wasting disease in mule deer $[2,5,12]$. They are caused by a unique agent believed by the majority of investigators to be "prions" - proteinaceous infectious particles compose entirely of the misfolded isoform $\left(\mathrm{PrPSc}^{\mathrm{Sc}}\right)$ of a normal cellular isoform $\left(\mathrm{PrPc}^{\mathrm{c}}\right)$ of prion protein [1].

The pathological changes in prion diseases are confined to the central nervous system. They include spongiform change, astro- and microglial proliferation, amyloid plaques in a proportion of cases and neuronal drop-out [20]. Neurons degenerate and die by either apoptosis or autophagy, or both $[6,7,14,15]$. A novel prion disease with autonomic disturbances and diarrhea was recently described [20]. 
The optic nerve, being in reality not a nerve but an extension of the central nervous system (CNS), is a unique model system to gain insight into what is going on within the CNS. We pioneered use of the optic nerve in electron microscopic study of transmissible spongiform encephalopathies $[8,16,18]$. We found, typical for CNS lesions, spongiform change, astrocytosis and a robust microglial/macrophage reaction. Recently, the optic nerve was used to study mechanisms of acute axonal degeneration following the crush of the nerve. Surprisingly, the major lesion was widespread autophagy. We thus returned to our archival material of the optic nerves from experimental CJD and GSS to find robust autophagy as well.

\section{Material and methods}

\section{Creutzfeldt-Jakob disease - strain, animals, incubation period of illness}

Outbred 6-week-old golden Syrian hamsters (Medical University of Lodz, Department of Oncology, Lodz, Poland) were inoculated intracerebrally with $0.05 \mathrm{ml}$ of a $10 \%(\mathrm{w} / \mathrm{v})$ centrifugation-clarified hamster brain suspension containing the Echigo- 1 strain of the CJD agent. Control animals were sham inoculated intracerebrally with the same volume of saline. We used five hamsters for each experiment; the control group consisted of two hamsters. In the first passage in our laboratory $\left(7^{\text {th }}\right.$ serial passage after initial isolation), the incubation period was approximately six months. The experiment was repeated twice, with similar results. Two uninfected hamsters were perfused identically.

\section{Gerstmann-Sträussler-Scheinker disease - strain, animals, incubation period of illness}

Five weanling 4- to 6-week-old NIH Swiss mice (Animal Production Area, Frederick Cancer Research Facility, Frederick, MD) were each inoculated intracerebrally with $0.03 \mathrm{ml}$ of a $10 \%(\mathrm{w} / \mathrm{v})$ clarified brain suspension of the Fujisaki strain of GSS (titer, $3.1 \times 10^{4} L_{50}$ per $0.03 \mathrm{ml}$, by intracerebral route). The incubation period ranged from 16 to 18 weeks. Two control animals were sham-inoculated with saline.

\section{Electron microscopy}

Hamsters in the terminal stage of CJD and control sham-inoculated hamsters at the same interval after inoculation were anaesthetized with ketamine. They were perfused by intracardiac injection with saline followed by $150 \mathrm{ml}$ of $1.25 \%$ glutaraldehyde and $1 \%$ paraformaldehyde prepared in cacodylate buffer $(\mathrm{pH} 7.4)$ and then by $50 \mathrm{ml}$ of $5 \%$ glutaraldehyde and $4 \%$ paraformaldehyde.

Five CJD- and two sham-inoculated mice were sacrificed by intracardiac perfusion using $180 \mathrm{ml}$ of $1.5 \%$ glutaraldehyde and $1 \%$ paraformaldehyde prepared in phosphate buffer ( $\mathrm{pH}$ 7.4). The differences resulted from experiments being performed at different times, but the quality of tissue preservation was excellent in both cases. From perfused animals, optic nerves were dissected and divided into three or four samples which were postfixed in $1 \%$ osmium tetroxide for 1 to 2 hours, dehydrated through a series of graded ethanols and propylene oxide, and embedded in Embed 812 (Electron Microscopy Sciences, Ft. Washington, PA).

\section{Results}

The optic nerves from control animals were unremarkable and consisted of innumerable axons containing no pathological structures. Lesions of both experimental GSS (Fujisaki-1) in mice and experimental CJD (Echigo-1) in hamsters were practically indistinguishable and an outline was published before $[17,19]$. Briefly, they consisted of widespread Wallerian degeneration, spongiform change and a glial reaction (Fig. 1). It must be stressed that dystrophic neurites were relatively rare - one or two per section (Fig. 2). The latter were filled with numerous mitochondria and lysosomal electron-dense bodies. Autophagic vacuoles defined as structures bound in double membranes were readily found in many neuronal processes (see the companion paper). The following description is organized as a sequence; however, the changes were all observed in the same specimens. First several empty double membrane-bound autophagic vacuoles were seen (Figs. 3-5). In several of those vacuoles, the inner membrane was separated from the outer membrane and enveloped cargo (Figs. 3 and 4). At the final stage, a mixture of empty autophagic vacuoles and electron-dense lysosomal vesicles was seen (Figs. 6A-B). Dystrophic neurites filled with a mixture of mitochondria, empty autophagic vacuoles and electron-dense lysosomal vesicles were interpreted as the final stage of autophagy (Fig. 7). We attempted to count autophagic vacuoles and autophagolysosomes but the results were ambiguous. In the majority of neurites during counting, we found lysosomal dense bodies as predominant structures; however, the reverse rela- 


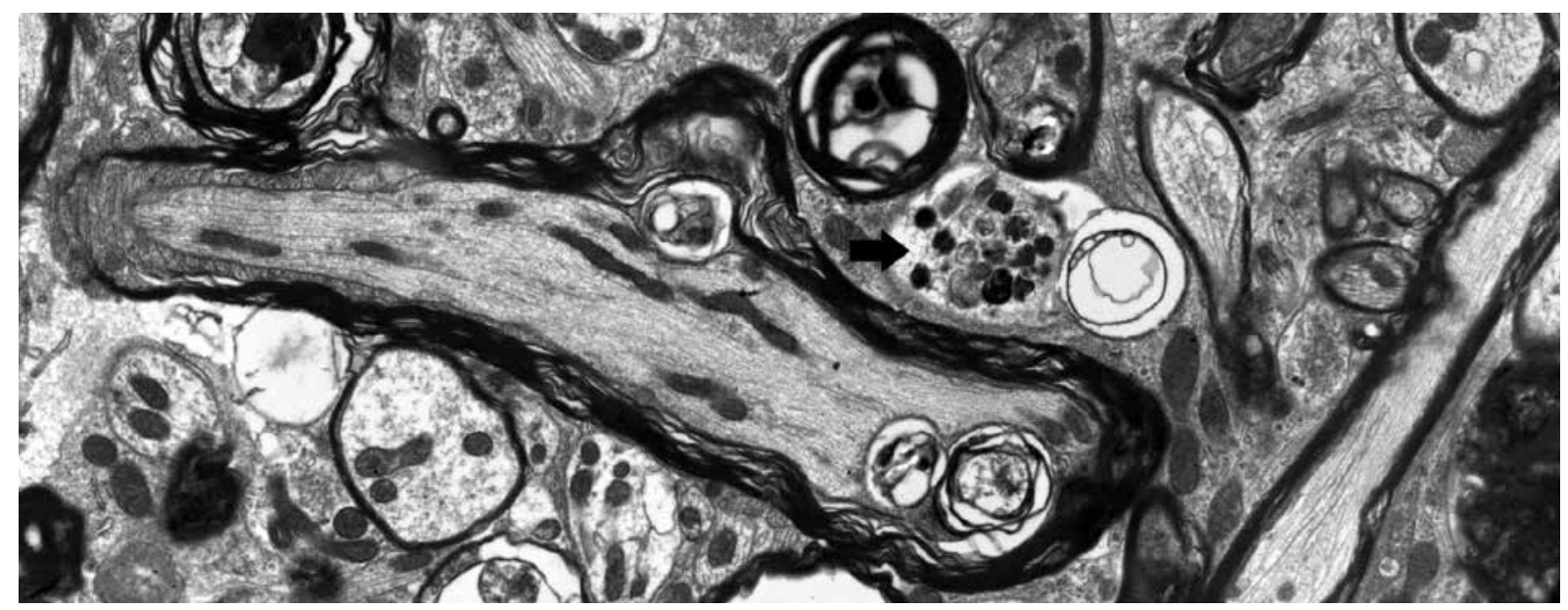

Fig. 1. General view of the optic nerve from a mouse infected with the Fujisaki-1 strain of Gerstmann-SträusslerScheinker disease. A dystrophic neurite is marked with an arrow. Original magnification, $\times 12000$.

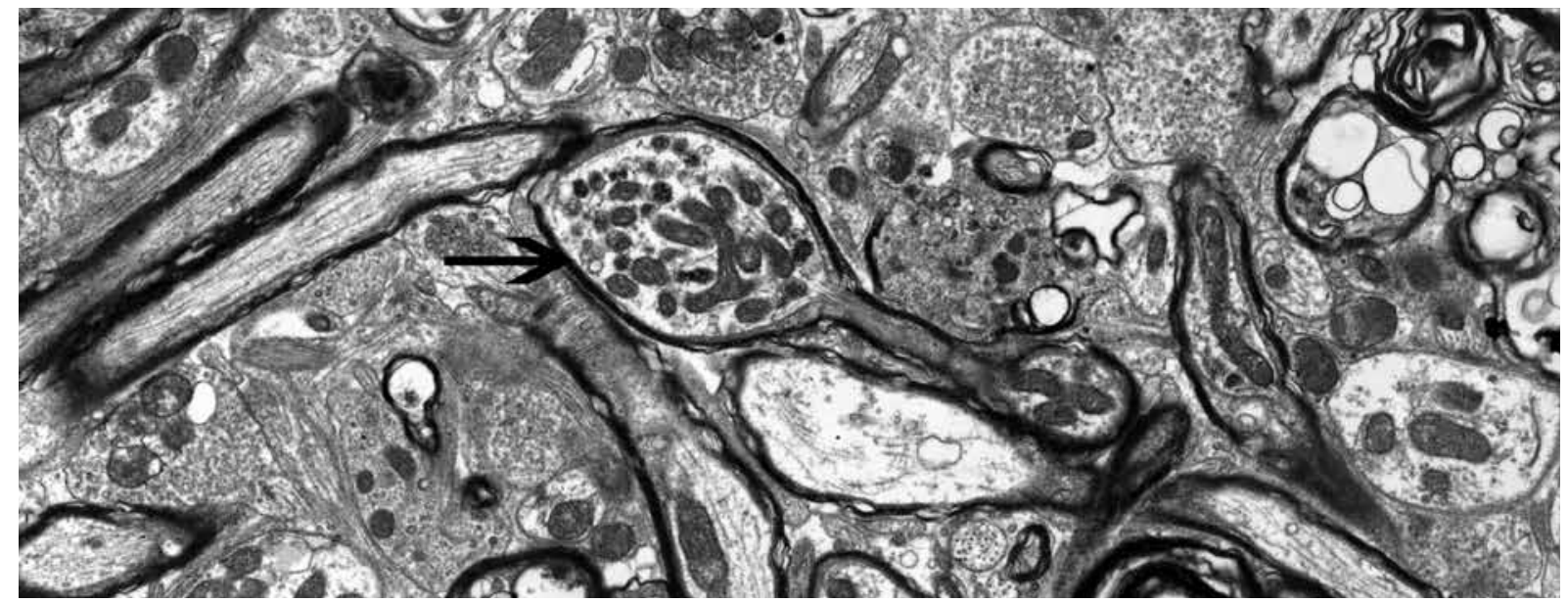

Fig. 2. Longitudinal section through the axon showing bullous swelling (arrow), a mouse infected with the

Fujisaki-1 strain of Gerstmann-Sträussler-Scheinker disease. Original magnification, $\times 12000$.

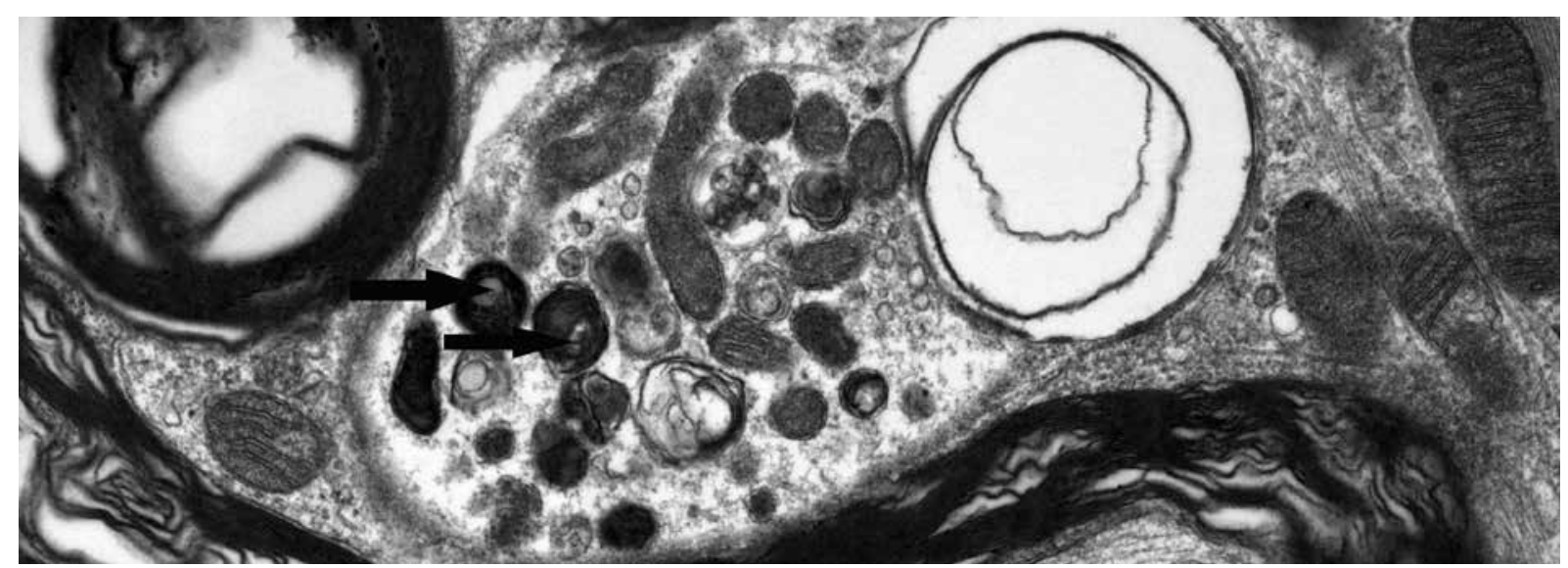

Fig. 3. Transverse section through the axonal process from a mouse infected with the Fujisaki-1 strain of Gerstmann-Sträussler-Scheinker disease. Numerous mitochondria are seen (arrows). Original magnification, $\times 12000$. 


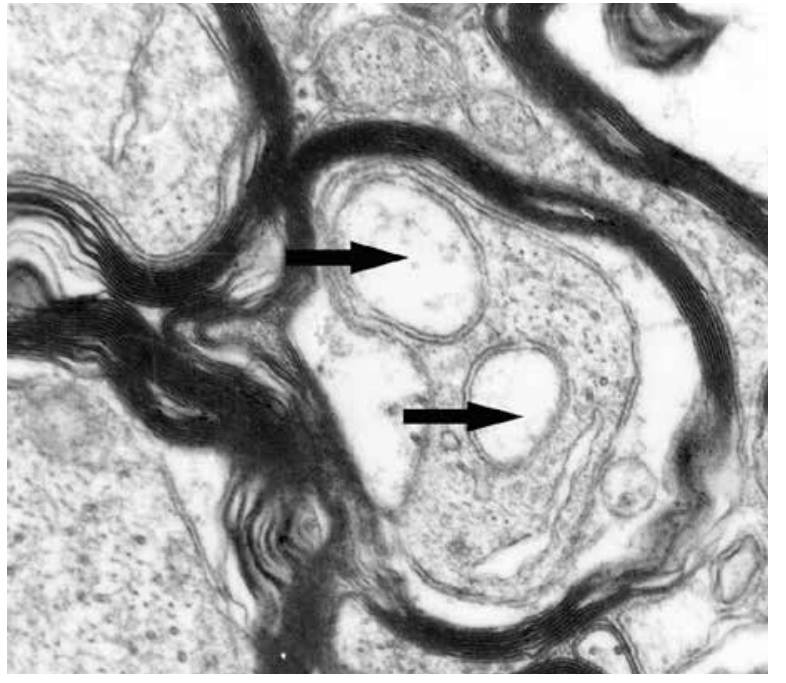

Fig. 4. Non-myelinated process from a mouse infected with the Fujisaki-1 strain of GerstmannSträussler-Scheinker disease. Two empty vacuoles (arrows). Original magnification, × 12000 .

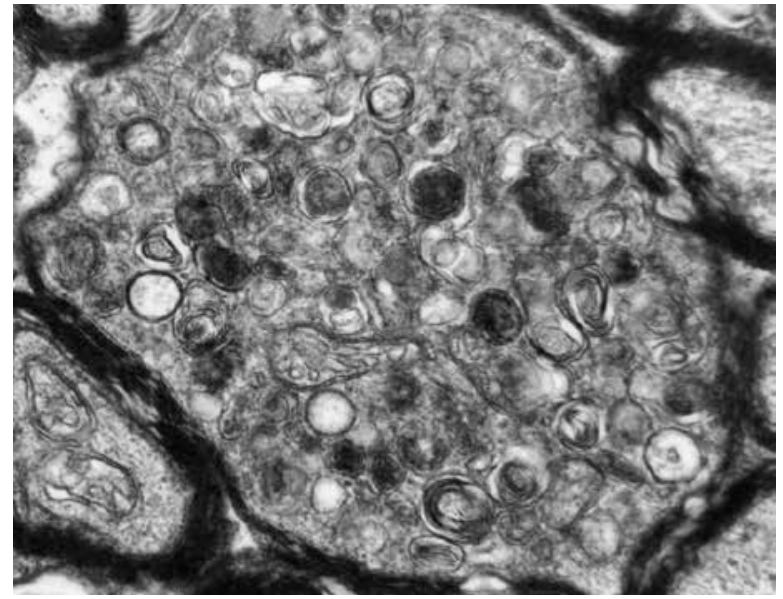

Fig. 5. Myelinated process from an optic nerve of a mouse infected with the Fujisaki strain of Gerstmann-Sträussler-Scheinker disease. The dystrophic neurites are completely filled with mitochondria and autophagic vacuoles. Original magnification, × 12000 .
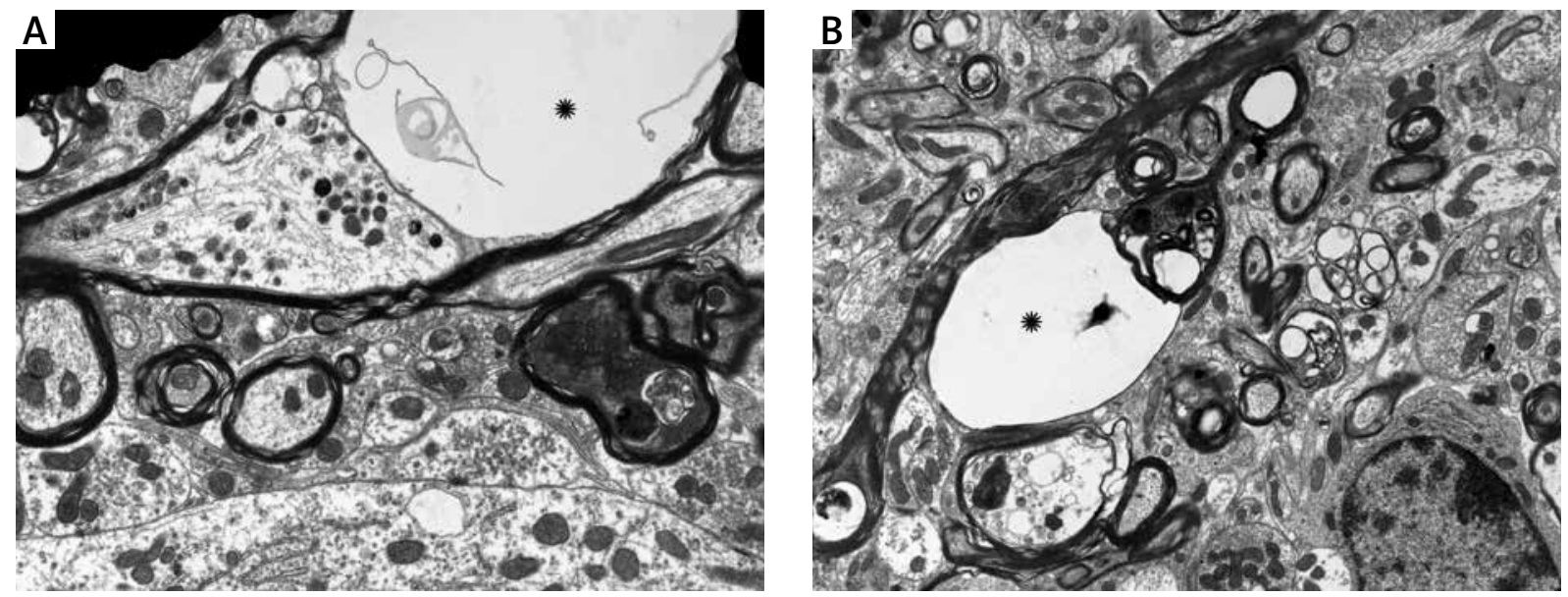

Fig. 6. A) Myelinated process from an optic nerve of a mouse infected with the Fujisaki strain of GerstmannSträussler-Scheinker disease (GSS). Note myelinated vacuole attached to a neurite (star). Original magnification, $\times 12$ 000. B) A myelinated process from an optic nerve of a mouse infected with the Fujisaki strain of GSS. Note myelinated vacuole attached to a neurite (star). Original magnification, $\times 12000$.

tionship was also observed. These results were probably dependent on the plane of sections and the stage of degeneration. Of note, several areas were replaced with dense astrocytic gliosis.

\section{Discussion}

We pioneered the work on the optic nerves in prion diseases [8,17-19] and demonstrated widespread myelinated axon damage, Wallerian degeneration and astrocytic and macrophagic reaction. It must be remembered that the optic nerve is not a nerve in the sense of a peripheral nerve; it is an extension of the CNS formed by and composed of retinal ganglion cells. The classification of dystrophic neurites is also variable [11; supplementary data]. The study of optic nerve injury may also have clinical significance with regard to Leber's optic nerve atrophy, glaucoma and trauma. Knöferle et al. [11] distinguished several types of spheroid formation: 1) acute, 


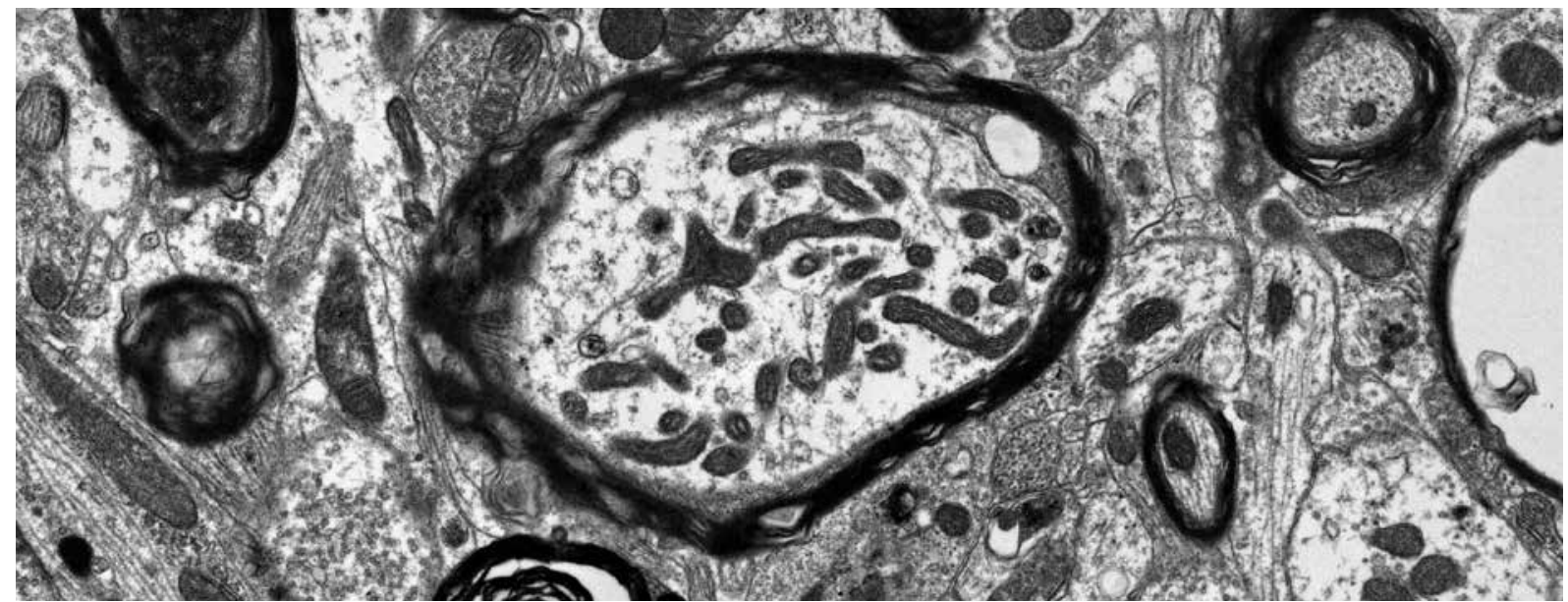

Fig. 7. Myelinated process from an optic nerve of a hamster infected with the Echigo-1 strain of CreutzfeldtJakob disease. Original magnification, × 12000 .

corresponding to those classically reported by Lampert [4], which is the most typical; neurites contain diverse subcellular organelles such as degenerating mitochondria and lysosomes; 2) those with "sparse axoplasm without regularly structured microtubules" and those transforming into electron lucent vacuoles. The latter may seem indistinguishable from typical "spongiform change" that is a hallmark of the whole group of prion diseases. Here we reported that, additionally, axons were packed with autophagic vacuoles. The observed changes varied and we plan now to extend our observations using a sequential study. It must also be stressed that axonal changes after damage to the optic nerve appear relatively early, some 30 minutes after transection, and this means that our observation taken at the terminal stage of disease may not be whole representative.

Those changes in the optic nerve are observed in many different conditions, for example in transgenic mice expressing mutant (P301L) human tau [9] and hereditary diffuse leukoencephalopathy with spheroids $[10,13]$, to mention just two, and the appearance of dystrophic neurites in every condition is practically identical [3].

In conclusion, we observed widespread autophagy in optic nerves in experimental CJD and GSS. The pathogenetic role of this phenomenon is unknown.

\section{Disclosure}

Authors report no conflict of interest.

\section{References}

1. Aguzzi A, Lakkaraju AK. Cell Biology of Prions and Prionoids: A Status Report. Trends Cell Biol 2016; 26: 40-51.
2. Gajdusek DC. Unconventional viruses and the origin and disappearance of kuru. Science 1977; 197: 943-960.

3. Klionsky DJ, Abdelmohsen K, Abe A, Abedin MJ, Abeliovich H, (...) Liberski PP, Sikorska B et al. Guidelines for the use and interpretation of assays for monitoring autophagy ( $3^{\text {rd }}$ edition). Autophagy 2016; 12: 1-222.

4. Lampert PW. A comparative electron microscopic study of reactive, degenerating, regenerating, and dystrophic axons. J Neuropathol Exp Neurol 1967; 26: 345-368.

5. Liberski PP. Prion diseases: a riddle wrapped in a mystery inside an enigma. Folia Neuropathol 2008; 46: 93-116.

6. Liberski PP, Brown DR, Sikorska B, Caughey B, Brown P. Cell death and autophagy in prion diseases (transmissible spongiform encephalopathies). Folia Neuropathol 2008; 46: 1-25.

7. Liberski PP, Sikorska B, Bratosiewicz-Wasik J, Gajdusek DC, Brown P. Neuronal cell death in transmissible spongiform encephalopathies (prion diseases) revisited: from apoptosis to autophagy. Int J Biochem Cell Biol 2004; 36: 2473-2490.

8. Liberski PP, Sikorska B, Bratosiewicz-Wasik J, Waliś A, Brown P, Brown D. Exuberant cellular reaction of the optic nerves in experimental Creutzfeldt-Jakob disease. Acta Neurobiol Exp (Wars) 2003; 63: 309-318.

9. Lin WL, Lewis J, Yen SH, Hutton M, Dickson DW. Ultrastructural neuronal pathology in transgenic mice expressing mutant (P301L) human tau. J Neurocytol 2003; 32: 1091-1105.

10. Lin WL, Wszolek ZK, Dickson DW. Hereditary diffuse leukoencephalopathy with spheroids: ultrastructural and immunoelectron microscopic studies. Int I Clin Exp Pathol 2010; 3: 665-674.

11. Knöferle J, Koch JC, Ostendorf T, Michel U, Planchamp V, Vutova P, Tönges L, Stadelmann C, Brück W, Bähr M, Lingor P. Mechanisms of acute axonal degeneration in the optic nerve in vivo. Proc Natl Acad Sci U S A 2010; 107: 6064-6069.

12. Prusiner SB. Biology and genetics of prions causing neurodegeneration. Annu Rev Genet 2013; 47: 601-623.

13. Shu Y, Long L, Liao S, Yang J, Li J, Qiu W, Yang Y, Bao J, Wu A, Hu X, Lu Z. Involvement of the optic nerve in mutated CSF1R-induced 
hereditary diffuse leukoencephalopathy with axonal spheroids. BMC Neurol 2016; 16: 171.

14. Sikorska B, Liberski PP, Giraud P, Kopp N, Brown P. Autophagy is a part of ultrastructural synaptic pathology in Creutzfeldt-Jakob disease: a brain biopsy study. Int J Biochem Cell Biol 2004; 36: 2563-2573.

15. Sikorska B, Liberski PP, Sobów T, Budka H, Ironside JW. Ultrastructural study of florid plaques in variant Creutzfeldt-Jakob disease: a comparison with amyloid plaques in kuru, sporadic Creutzfeldt-Jakob disease and Gerstmann-Sträussler-Scheinker disease. Neuropathol Appl Neurobiol 2009; 35: 46-59.

16. Sikorska B, Waliś A, Bratosiewicz-Wasik J, Brown P, Liberski PP. Fate of myelinated fibres in the optic nerves in experimental Creutzfeldt-Jakob disease in rodents: an ultrastructural study. Folia Neuropathol 2004; 42: 101-105.

17. Waliś A, Bratosiewicz J, Sikorska B, Brown P, Gajdusek DC, Liberski PP. Ultrastructural changes in the optic nerves of rodents with experimental Creutzfeldt-Jakob Disease (CJD), Gerstmann-Sträussler-Scheinker disease (GSS) or scrapie. J Comp Pathol 2003; 129: 213-225.

18. Waliś A, Liberski PP, Brown P. Ultrastructural alterations in the optic nerve in transmissible spongiform encephalopathies or prion diseases--a review. Folia Neuropathol 2004; 42 Suppl B: 153-160.

19. Waliś A, Liberski PP, Brown P, Gajdusek DC. Electron microscopic studies of the optic nerve in experimental scrapie and the panencephalopathic type of Creutzfeldt-Jakob disease. Folia Neuropathol 1997; 35: 255-258.

20. Will RG, Ironside JW. Sporadic and Infectious Human Prion Diseases. Cold Spring Harb Perspect Med 2017; 7: pii: a024364. 